\title{
Value Addition to Red Sediment Placer Sillimanite Using Microwave Energy and in Depth Structural and Morphological Characterization of Mullite
}

\author{
Satya Sai Srikant ${ }^{1}$, Saroj Kumar Singh ${ }^{2}$, Partha Sarathi Mukherjee ${ }^{2}$, Raghupatruni Bhima Rao ${ }^{3}$ \\ ${ }^{1}$ Sri Ramaswamy Memorial University, Delhi NCR Campus, Modinagar, India \\ ${ }^{2}$ Council for Scientific and Industrial Research (CSIR), Institute of Minerals and Materials Technology, Bhubaneswar, India \\ ${ }^{3}$ Aryan Institute of Engineering and Technology, BP University of Technology, Bhubaneswar, India \\ Email: satya.srikant@gmail.com
}

Received July 1, 2012; revised August 3, 2012; accepted August 13, 2012

\begin{abstract}
This paper deals with the effect of microwave energy for mullite formation from placer sillimanite. A mullite formation is seen when $60 \% \mathrm{SiC}$ and $5 \%$ binder are used with the composite charge material, i.e. sillimanite $(60 \%)$ and $\mathrm{Al}_{2} \mathrm{O}_{3}$ $(40 \%)$. The maximum temperature of the microwave sintering furnace achieved is $1355^{\circ} \mathrm{C}$ at $2450 \mathrm{~W}$ microwave power. Addition of $10 \%$ binder to the same charge material with $60 \% \mathrm{SiC}$, the furnace temperature achieved is $1384^{\circ} \mathrm{C}$ at microwave power $1900 \mathrm{~W}$. Mullite is formed within 25 minutes from the sillimanite, under the above experimental conditions. Whereas under the similar additive conditions, the mullite formed from sillimanite in conventional furnace heating, it took 3 hours at $1300^{\circ} \mathrm{C}$. XRD data show the mullite phase for both the products obtained from microwave sintering furnace and conventional furnace. FESEM image analysis shows the mullite formations, SiC fibrous cluster and alumina needles in microwave treated sample. Thus microwave heat source is much more effective for value addition to red sediment placer sillimanite to form mullite in compare to conventional furnace.
\end{abstract}

Keywords: Microwave Heat Energy; Sillimanite; Mullite; Value Addition

\section{Introduction}

This paper provides a simple theoretical model to investigate determinants of the vertical IIT based on Bertrand price competition. We find that the volume of trade is higher among countries where R\&D investments are larger. In addition, the vertical IIT share increases with the similarity between two countries in terms of technology and per-capita income. Our theoretical findings are consistent with recent empirical findings.

\section{Introduction}

Red sediments in India are recent geological formations. These red sediments occur in badlands topography. These sediments essentially contain industrial placer heavy minerals such as ilmenite, sillimanite, rutile, zircon, monazite and other heavy minerals. Sillimanite $\left(\mathrm{Al}_{2} \mathrm{O}_{3} \cdot \mathrm{SiO}_{2}\right)$ is mineral which has special property of undergoing conversion into mullite $\left(3 \mathrm{Al}_{2} \mathrm{O}_{3} \cdot 2 \mathrm{SiO}_{2}\right)$ and vitreous silica (cristobalite) on heating between $1350^{\circ} \mathrm{C}$ and $1500^{\circ} \mathrm{C}$. Thus the placer minerals which contain considerable amount of sillimanite can be made use of mulite formation for industrial applications. The decomposition of sil- limanite to mullite and silica is as follows

$$
2\left(\mathrm{Al}_{2} \mathrm{O}_{3} \cdot \mathrm{SiO}_{2}\right) \rightarrow 3 \mathrm{Al}_{2} \mathrm{O}_{3} \cdot 2 \mathrm{SiO}_{2}+\mathrm{SiO}_{2}
$$

On heating the placer sillimanite between $1500^{\circ} \mathrm{C}$ and $1650^{\circ} \mathrm{C}$ with conventional heating process, it decomposes to mullite and silica [1] in such a way that their decompositions produce a mixture of the mullite $3: 2$ plus free silica. Due to presence of rejected silica phase, the impurities become segregated at the grain boundaries. However, it is logical to believe that incorporating alumina to react with the rejected silica to form a single-phase mullite structure can minimize this disadvantage. Use of conventional furnaces for preparation of mullite from sillimanite is a universally known process. Several publications and patents are available in the literature on this aspect. Literature pertaining on the preparation of mullite using microwave heat source is very much restricted. The ava ilable literature is on formation of mullite from kaolinite or kaolin clay. The literature reveals that Elias and Ruth [2] observed the mullite phase in XRD analysis for the sample treated by microwave carbothermal reduction of kaolin. Ebadzadeh, et al. [3] observed about mullite behavior from the reaction sintering of clay and alumina 
heated in a microwave oven. According to them, alumina and clay exhibit low dielectric losses $(0.1 \pm 0.03$ and $<1$, respectively) and are difficult to heat in a microwave oven at room temperature, therefore $\mathrm{SiC}$ crucible with a high dielectric loss $(300 \pm 50)$ were used which behave as a susceptor. They also observed that after microwave processing, the minimum temperature required for the presence of mullite residual phase was $1250^{\circ} \mathrm{C}$. However, so far no attempt is made to investigate the effect of microwave heat treatment on placer sillimanite for mullite formation in microwave sintering furnace, as all attempts have been made for mullite formation with conventional furnace on kaolin clay or fly ash [4] using microwave oven only. Hence it is felt necessary to study the effect of microwave heat on sillimanite for formation of mullite using microwave sintering furnace. The present study deals with the mullite formation from placer sillimanite using microwave sintering furnace.

\section{Materials and Methods}

\subsection{Raw Materials}

Placer sillimanite $\left(\mathrm{Al}_{2} \mathrm{SiO}_{5}\right)$ recovered from the red sediments of badlands topography, near Nolia Nuagam Odisha, India. The recovery process and its chemical composition are described in the methodology. The location map for Nolia Nuagam, Odisha is shown in Figure 1.

The sample collection points $(\rightarrow)$ of red sediments [(a) red sediment hillock and (b), (c) \& (d) heavy mineral placer concentrations] at Nolia Nuagam, Odisha, India is shown in Figure 2. The 250 meshed $\mathrm{SiC}$ powder and alumina $\left(\alpha-\mathrm{Al}_{2} \mathrm{O}_{3}, \mathrm{~d}_{90}<10 \mathrm{~mm}\right)$ were used in the present study.

\subsection{Recovery of Sillimanite}

The experimental plan for recovery of placer sillimanite mineral from red sediments of badlands topography is shown in Figure 3. The high grade placers having mineral

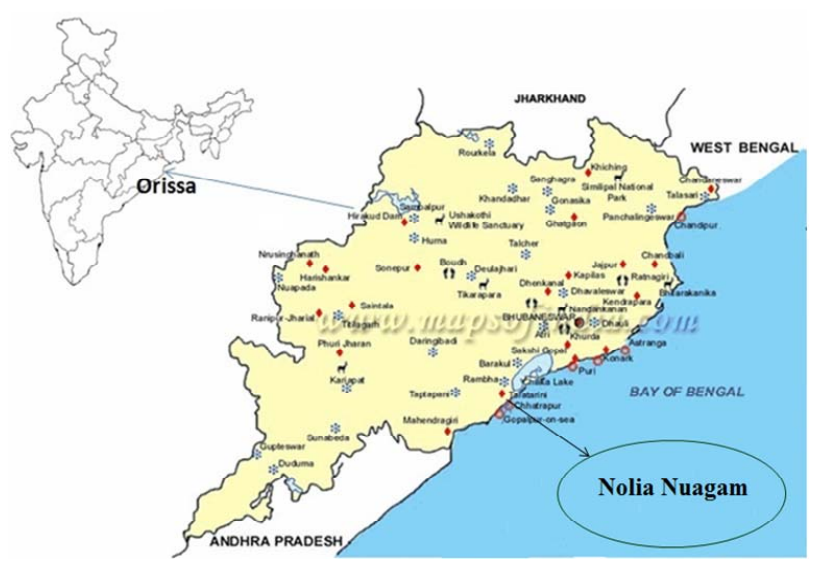

Figure 1. Location of the red sediment deposits of Nolia Nuagam, Odisha, India.

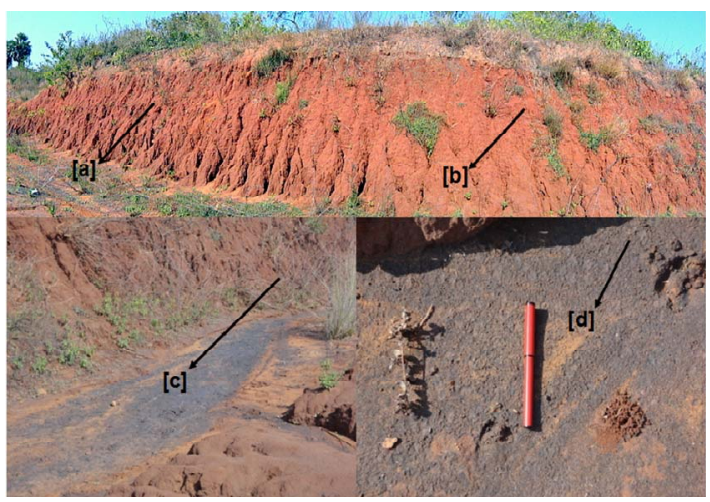

Figure 2. Sample collection points $(\rightarrow)$ of red sediments at Nolia Nuagam, Odisha, India [(a): red sediment hillock, (b), (c) \& (d): heavy mineral concentrations].

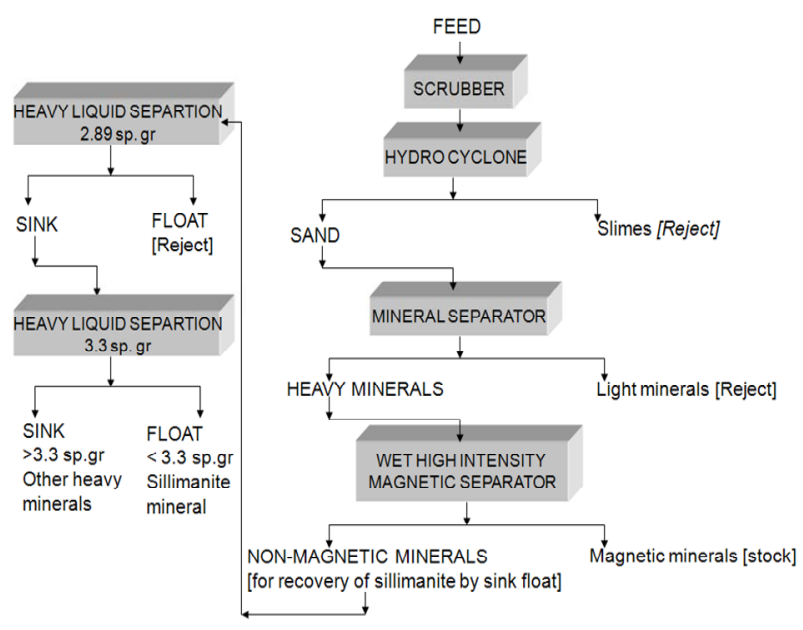

Figure 3. Experimental plan for recovery of sillimanite mineral from red sediments of badlands topography.

concentrate containing greater than $63 \%$ of total heavy minerals were scrubbed initially in an alkaline medium. The slimes were rejected. The sand was subjected to magnetic separation for recovery of non magnetic sillimanite and other associated heavy minerals. The non magnetic fraction was subjected to sink float tests using bromoform ( 2.89 sp.gr) and methylin iodide ( 3.3 sp.gr). The non magnetic methylin iodide float is sillimanite. The recovered sillimanite was used in the present investigations.

\subsection{Effect of Microwave Treatment on Sillimanite}

The recovered sillimanite from red sediments containing $56.67 \% \mathrm{Al}_{2} \mathrm{O}_{3}$ was used in all the experiments. In all experiments $60 \%$ sillimanite was used as constant parameter. The samples in form of pellets were made with the combination of sillimanite $\left(\mathrm{Al}_{2} \mathrm{SiO}_{5}\right)$, alumina $\left(\mathrm{Al}_{2} \mathrm{O}_{3}\right)$ and additives of silicon carbide $(\mathrm{SiC})$ powder in various ratios. These samples were then placed inside the microwave 
sintering furnace separately in order to study the effect of microwave heating.

The microwave sintering furnace used in the present investigation was G N Tech, $37.500 \mathrm{~W}, 2.45 \mathrm{GHz}$. An adequate argon pressure is maintained in microwave furnace in order to avoid any type of oxidation reaction. The susceptor $\mathrm{SiC}$ placed near to sample further to facilitate the microwave absorption and heating the sample in microwave sintering furnace [5]. The susceptor $\mathrm{SiC}$ is placed diagonally to the sample in microwave sintering furnace. Experiments were conducted in microwave furnace by changing ratio samples such as $\mathrm{SiC}$ powder and alumina $\left(\mathrm{Al}_{2} \mathrm{O}_{3}\right)$ variables and at constant $60 \%$ sillimanite by weight. On taking consideration that the minimum temperature required to form the mullite is $1250^{\circ} \mathrm{C}$, the different samples were heated separately either by varying the duration of time or by varying the power fed with respect to variation of $\mathrm{SiC}$ powder and alumina $\left(\mathrm{Al}_{2} \mathrm{O}_{3}\right)$. Experiments were also carried out in conventional furnace to achieve the mullite phase. The resulting products were characterized by X-Ray diffraction, FESEM and EDAX.

\subsection{Analytical Methods}

The PANalytical X-Pert X-Ray powder diffractometer with Mo-K $\alpha$ radiation $(\lambda=0.709 \AA)$ from $6^{\circ}$ to $40^{\circ}$ scanning angle at a scanning rate of $0.02^{\circ} / \mathrm{sec}$ was used for phase analysis of present investigation. Morphological features of mullite were studied using the FESEM (model: Supra55; Zeiss, Germany). The FESEM has a resolution of $1 \mathrm{~nm}$ at $30 \mathrm{KV}$ which is equipped with $20 \mathrm{~mm}^{2}$. Oxford's Energy dispersive X-ray spectroscopy (EDS) detector for imaging of conducting as well as non-conducting samples without gold coating. SEM/EDAX studies were done by using Hitachi VP-SEM S-3400N. It has high $\mathrm{SE}$ resolution of $10 \mathrm{~nm}$ at $3 \mathrm{KV}$. The magnification of the instrument is $5 \mathrm{X}-300.000 \mathrm{X}$; alternating voltage is $0.3-30 \mathrm{KV}$. The grains were mounted on a SEM brass stub. The mounted grains were coated with gold in a vacuum evaporator while the mullite sample was being slowly rotated. Mullite and silicon carbide materials were analyzed to know the weight $\%$ of various constituents of atoms using EDAX.

\section{Results and Discussion}

\subsection{Characterization of Raw Material}

The chemical analysis of red sediment placer sillimanite given in Table 1 indicate that the sample contain $56.67 \%$ $\mathrm{Al}_{2} \mathrm{O}_{3}, 25.21 \% \mathrm{SiO}_{2}, 0.51 \% \mathrm{TiO}_{2}$ and $0.23 \% \mathrm{Fe}_{2} \mathrm{O}_{3}$. The modal analysis of red sediment feed sample is shown in Figure 4. The data indicate that the deslimed feed sample contain $7 \%$ sillimanite, $51 \%$ ilmenite, $1 \%$ zircon, $25 \%$ quartz, $2 \%$ rutile, $12 \%$ slimes and $2 \%$ others. The
XRD pattern of deslimed feed shown in Figure 5 indicates that the sample contain ilmenite, quartz, sillimanite are abundant minerals followed by rutile, zircon, hematite.

\subsection{Studies on Formation of Mullite from Sillimanite Using Microwave Sintering Furnace}

It is a known fact that microwave sintering furnace has a wide range of applications in mineral and material technology. In microwave heating of minerals, the materials which couple to microwave radiation contain dipoles $[5,6]$. These dipoles align themselves in an applied elec-

Table 1. Complete chemical analysis of the sillimanite concentrate.

\begin{tabular}{cc}
\hline Compound Name & Conc. (\%) \\
\hline $\mathrm{Al}_{2} \mathrm{O}_{3}$ & 56.67 \\
$\mathrm{SiO}_{2}$ & 40.21 \\
$\mathrm{TiO}_{2}$ & 0.51 \\
$\mathrm{Fe}_{2} \mathrm{O}_{3}$ & 0.23 \\
$\mathrm{CaO}$ & 0.42 \\
$\mathrm{MgO}$ & 0.31 \\
\hline
\end{tabular}

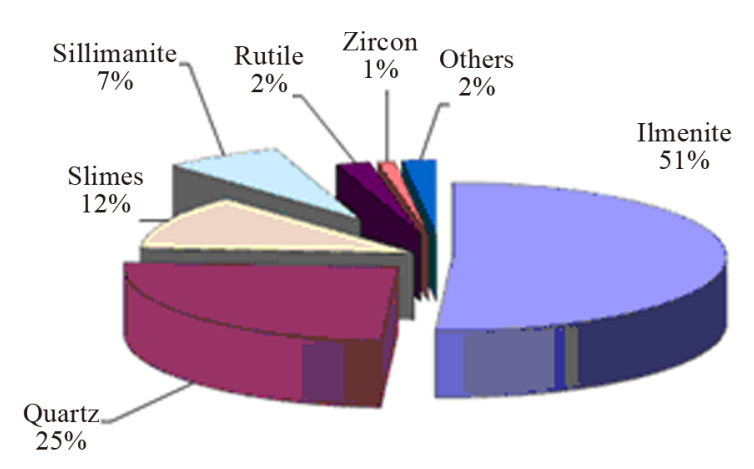

Figure 4. Modal analysis of red sediment feed sample.

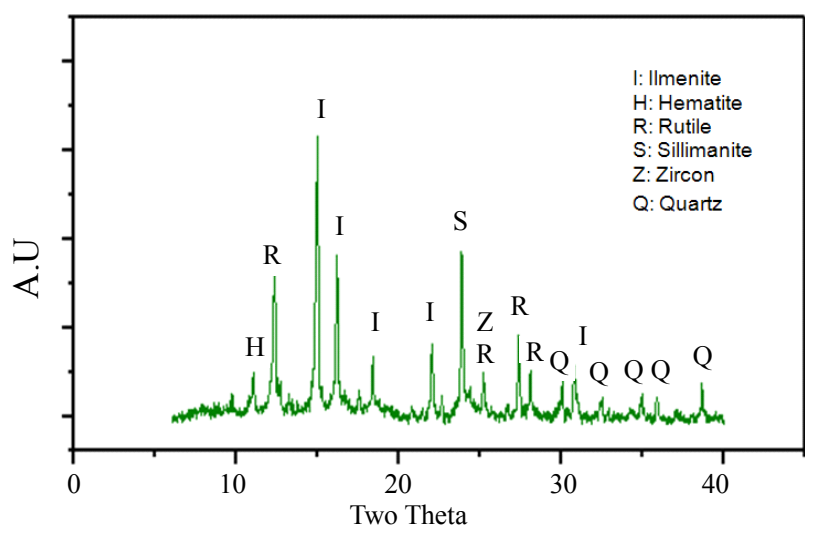

Figure 5. XRD pattern of deslimed feed. 
tric field and will flip around in an alternating electric field. As a consequence, the material will be heated as the stored internal energy [5-7] is lost to friction. This energy mode conversion has the advantage of being selective to individual mineral phases within a mass by which the mullite is formed from sillimanite.

The results of microwave power on mullite formation from sillimanite using $\mathrm{SiC}$ as susceptors are given in Table 2 . It may be noted here the role of $\mathrm{SiC}$ in the microwave sintering furnace is as a heating agent because it couples quickly with electromagnetic radiation, creating heating owing to the Joule effect. The decomposition of sillimanite with addition of $\mathrm{Al}_{2} \mathrm{O}_{3}$ and $\mathrm{SiC}$ may be expected as

$2\left(\mathrm{Al}_{2} \mathrm{O}_{3} \cdot \mathrm{SiO}_{2}\right)+\mathrm{Al}_{2} \mathrm{O}_{3}+\mathrm{SiC} \stackrel{\text { SiC Susceptor }}{\longrightarrow} 3 \mathrm{Al}_{2} \mathrm{O}_{3} \cdot 2 \mathrm{SiO}_{2}$

It is also an important fact to express at this point that the desired temperature for decomposition of sillimanite to mullite and silica is in the temperature range of $1300^{\circ} \mathrm{C}-1700^{\circ} \mathrm{C}$. It is observed from Table 2 that mullite is not formed with the charge sample containing sillimanite $(60 \%)$ and $\mathrm{Al}_{2} \mathrm{O}_{3}(40 \%)$ alone. This is due to the fact that maximum temperature of the microwave sintering furnace achieved is $805^{\circ} \mathrm{C}$ only. This effect can clearly be seen in Figure 6 where the effect of different variables such as $\mathrm{SiC}$ as additive and binder on the achievement of temperature $\left({ }^{\circ} \mathrm{C}\right)$ with microwave power fed (Watt) is expressed. It is further seen that from Figure 6 that the temperature of the microwave sintering furnace is not increasing beyond $805^{\circ} \mathrm{C}$ even with increasing of microwave power beyond 2850 Watt.

An increase in microwave power led to an increase in the heating rate of the samples with the combination of sillimanite, alumina, silicon carbide shows an affinity for microwave radiation, i.e., it heats effectively with increase of the applied power and as a consequence the temperature of the sample inside the furnace rises (measured by infrared pyrometer).

The transfer of energy does not rely on diffusion of heat from the surfaces and it is possible to achieve rapid and uniform heating of sample volumetrically [6-8].

Table 2. Results of microwave energy on mullite formation from sillimanite using $\mathrm{SiC}$ susceptor.

\begin{tabular}{cccccc}
\hline $\begin{array}{c}\text { Charge Sample } \\
\text { [Sillimanite }+ \\
\left.\mathbf{A l}_{2} \mathbf{O}_{3}\right]\end{array}$ & $\begin{array}{c}\text { SiC as } \\
\text { Additive } \\
(\%)\end{array}$ & $\begin{array}{c}\text { Binder } \\
(\%)\end{array}$ & $\begin{array}{c}\text { Microwave } \\
\text { Power (W) }\end{array}$ & $\begin{array}{c}\text { Max Temp } \\
\text { reached } \\
\left({ }^{\circ} \mathbf{C}\right)\end{array}$ & $\begin{array}{c}\text { Findings } \\
\text { (Mullite } \\
\text { formed) }\end{array}$ \\
\hline $60 \%+40 \%$ & Nil & 0 & 2850 & 805 & No \\
$60 \%+40 \%$ & 5 & 5 & 3000 & 1050 & No \\
$60 \%+40 \%$ & 40 & 5 & 2950 & 1080 & No \\
$60 \%+40 \%$ & 60 & 5 & 2372 & 1355 & Yes \\
$60 \%+40 \%$ & 60 & 10 & 1900 & 1384 & Yes \\
\hline
\end{tabular}

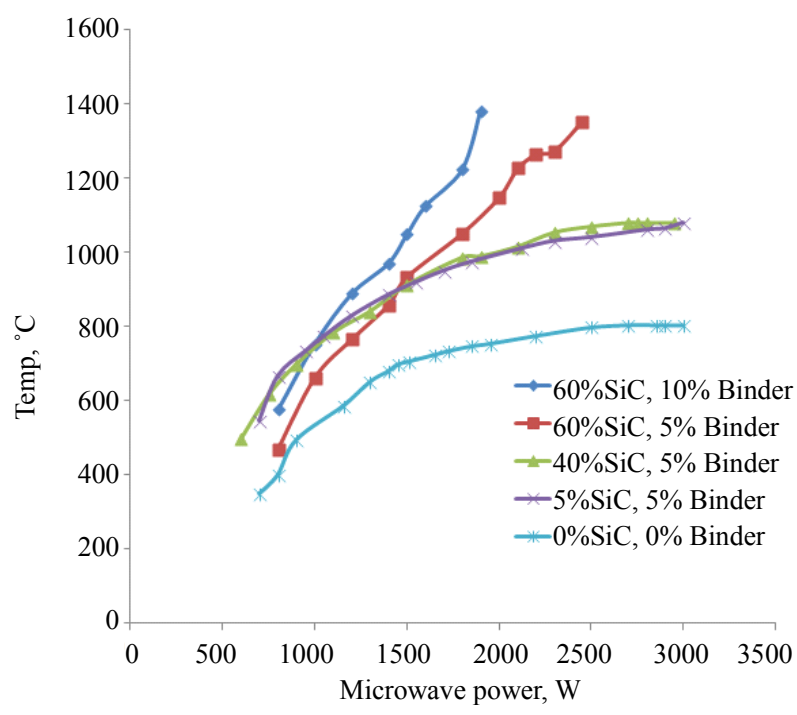

Figure 6. Effect of different variables on achievement of temperature with microwave power fed.

The results seen in Table 2 on the effect of different variables such as $5 \% \mathrm{SiC}$ and $40 \% \mathrm{SiC}$ with $5 \%$ binder to achieve the desired temperature around $1300^{\circ} \mathrm{C}$ for mullite formation from sillimanite is not seen and hence mullite has not been formed in both the conditions.

It is seen from the experiments that the temperature occurred for given microwave power to form mullite is increasing with addition of $\mathrm{SiC}$. The $\mathrm{SiC}$ is one of the reducing agents, which heat rapidly in presence of applied electric field. They conduct energy into the bulk sample so that electrons in non-dielectric materials can become more mobile. Due to this extra mobility, there is the formation of dipoles $[5,9]$ in the microwave field and the material can heat on its own. It is an established fact that microwave energy has potential for the speedy and efficient heating of minerals and in a commercial context may provide savings in both time and energy. The role of $\mathrm{SiC}$ powder of 250 mesh in the present investigation is not only behave as reducing agent but also as heating agent owing to it couples with microwaves creating heating, essential to proceed reactions $[9,10]$. Also as mentioned earlier that on increasing the microwave power led to an increase in the heating rate of the samples shows an affinity for microwave radiation, i.e., it heats effectively with increase of the applied power and as a consequence the temperature of the sample inside the furnace rises which is measured by infrared pyrometer.

Thus a mullite formation is seen when $60 \% \mathrm{SiC}$ and $5 \%$ binder are used with the composite charge material i.e. sillimanite $(60 \%)$ and $\mathrm{Al}_{2} \mathrm{O}_{3}(40 \%)$. The maximum temperature of the microwave sintering furnace achieved is $1355^{\circ} \mathrm{C}$ at $2450 \mathrm{~W}$ microwave power. Addition of $10 \%$ binder to the same charge material with $60 \% \mathrm{SiC}$, the furnace temperature achieved is $1384^{\circ} \mathrm{C}$ at microwave 
power $1900 \mathrm{~W}$. Hence when the sillimanite is exposed for 25 minutes, a mullite is formed under these experimental conditions. During microwave processing, the potential energy exists to reduce processing time and enhance product quality as microwaves can transfer energy throughout the sample volumetrically.

\subsection{Studies on Formation of Mullite from Sillimanite Using Conventional Furnace}

The experimental results on the formation of mullite from sillimanite using conventional furnace with the charge sample containing sillimanite $(60 \%)$ and $\mathrm{Al}_{2} \mathrm{O}_{3}(40 \%)$ and additives with $40 \% \mathrm{SiC}$ and $10 \%$ binder reveals that it took three hours to form a mullite at $1300^{\circ} \mathrm{C}$.

It is important to mention here the observations once again on the tests carried out with conventional furnace and microwave furnace that a mullite formation is seen at 25 minutes of experimental duration with microwave furnace and where as the formation of mullite is not seen with conventional furnace during 25 minutes under optimum material variables. It has taken three hours of time at $1300^{\circ} \mathrm{C}$ furnace temperature for formation mullite using conventional furnace.

The heating mechanism through microwaves furnace are distinctly different form that in the conventional furnace. Typical Figure 7 shows a schematic illustration of the process steps and effect of the heating mechanism in the carbothermal reduction reaction for microwaves furnace and conventional furnace with the charge material kaolin clay [2].

In the microwaves furnace, the heating with microwaves started in the central region of the pellets, resulted in two distinct zones: darker central core completely surrounded by lighter zone. It is also observed that the outer zone for MWCR as shown in Figure 7 is primarily mullite with a small percentage of $\mathrm{Al}_{2} \mathrm{O}_{3}$ and much less $\mathrm{SiC}$ than in the central zone with primarily $\mathrm{SiC}$ and small percentages of mullite and $\mathrm{Al}_{2} \mathrm{O}_{3}$. Both $\mathrm{CO}$ and $\mathrm{SiO}$ gases must diffuse out of the pellets. However, during conventional heating as shown in Figure 7, the carbothermal reaction began outer the pellets and then progressed into

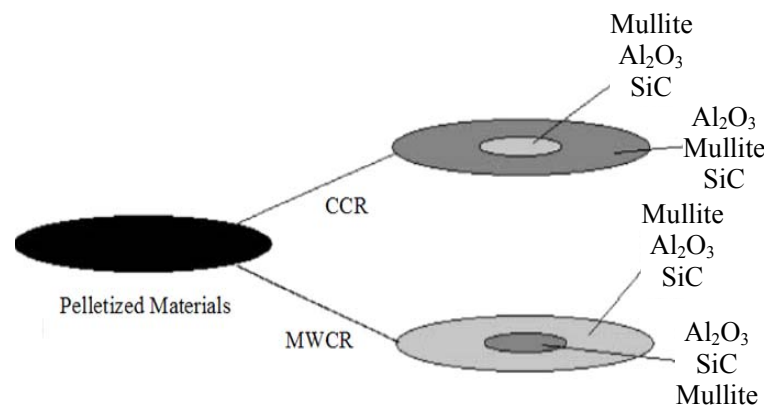

Figure 7. Effect of heating mechanism for the carbothermal reduction for both CCR and MWCR. the central core. The pellet showed two distinct zones: lighter central region completely surrounded by a darker zone. It was also observed that the outer zone was primarily mullite with small percentages of $\mathrm{SiC}$, whereas the inner region was primarily mullite with a small percentage of $\mathrm{SiO}_{2}$ and much less $\mathrm{SiC}$ than in the outer zone.

Thus it is concluded that during microwave processing, the potential energy exists to reduce processing time and enhance product quality as microwaves can transfer energy throughout the sample volumetrically. Hence microwave heat source is much effective for value addition to red sediment placer sillimanite to form mullite in compare to conventional furnace.

\subsection{Structural and Morphological Characterization of Mullite}

The XRD patterns of charge materials and additives such as sillimanite, alumina, silicon carbide and composite charge material (raw mullite) are shown in Figure 8. The XRD patterns of mullite formation in both microwave furnace and conventional furnace are also shown in Figure 9.

The XRD data indicate that the mullite formation in both microwave furnace and conventional furnace are almost similar with reference to mullite phase concern. The results evidenced that microwave is more efficient to produce $\mathrm{Al}_{2} \mathrm{O}_{3} /$ mullite $/ \mathrm{SiC}$ composite at $25 \mathrm{~min}$ than conventional furnace at $1300^{\circ} \mathrm{C} / 3 \mathrm{~h}$ duration.

The FESEM images for mullite formation from red sediment placer sillimanite using microwave heat treated is shown in Figure 10. It can clearly be seen that $\mathrm{SiC}$ (massive form), and mullite in cluster structure, are observed in the morphological features of mullite formed from red sediment placer sillimanite using microwave furnace.

It may be noted here that as the metal melts at high temperatures, it attracts $\mathrm{Si}$ and $\mathrm{C}$ atoms from the vapor to the catalyst to form whiskers. When saturation of these atoms occurred in the liquid catalyst, the growth is side branched type, resulting in formation of fibrous structure [11]. Apart from this, the alumina needles are also found and seen in the SEM image. This alumina phase is very helpful in microwave heating because it helps to isolate silica from silicon carbide during mullite formation.

Typical SEM EDAX data and image mapping for Al, $\mathrm{Si}, \mathrm{C}$ and $\mathrm{O}$ of microwave mullite are shown in Figures 11 and 12 respectively.

The image mapping for $\mathrm{Al}, \mathrm{Si}$, carbon and oxygen for typical mullite sample prepared from red sediment placer sillimanite using microwave sintering furnace reveals that the sample contain both mullite and $\mathrm{SiC}$ materials. Thus the data obtained from XRD, SEM EDAX confirm the findings on the presence of mullite and silicon carbide 


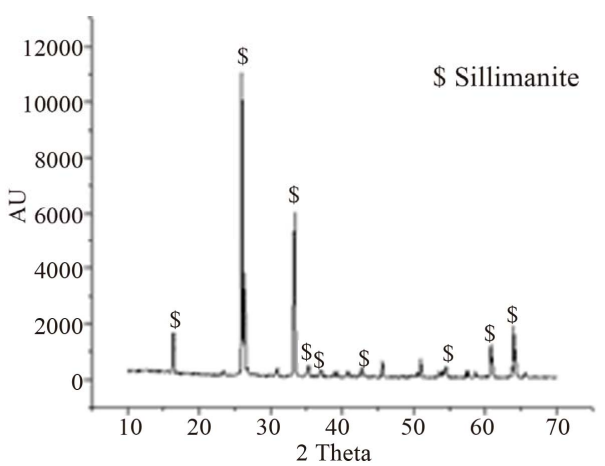

(a)

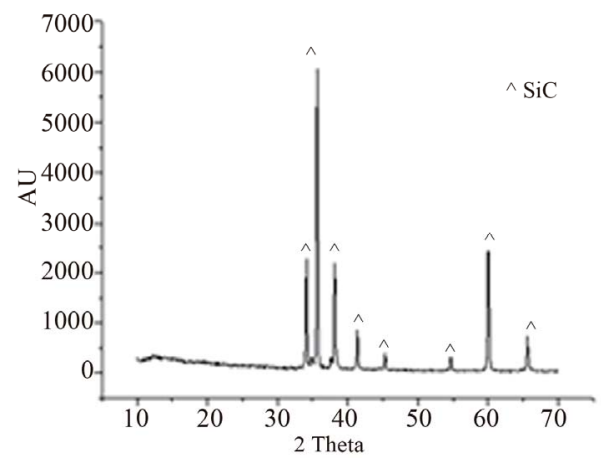

(c)

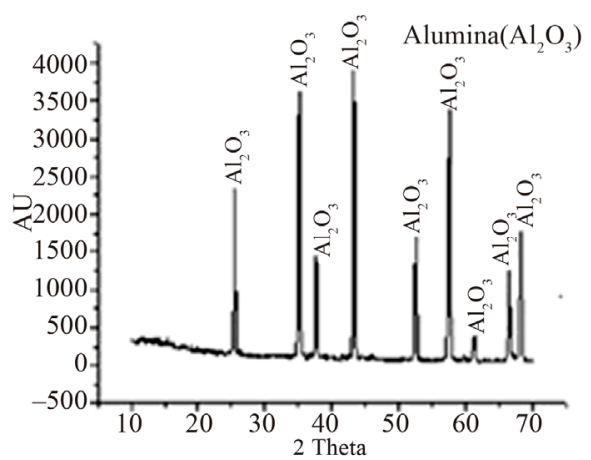

(b)

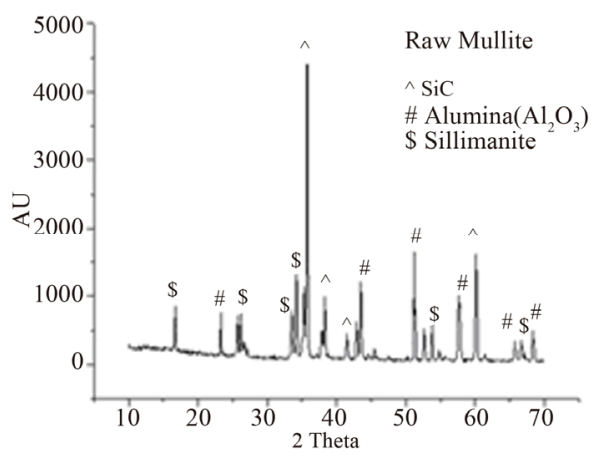

(d)

Figure 8. XRD patterns (Cu target) of (a) sillimanite (b) alumina (c) $\mathrm{SiC}$ and (d) raw mullite.

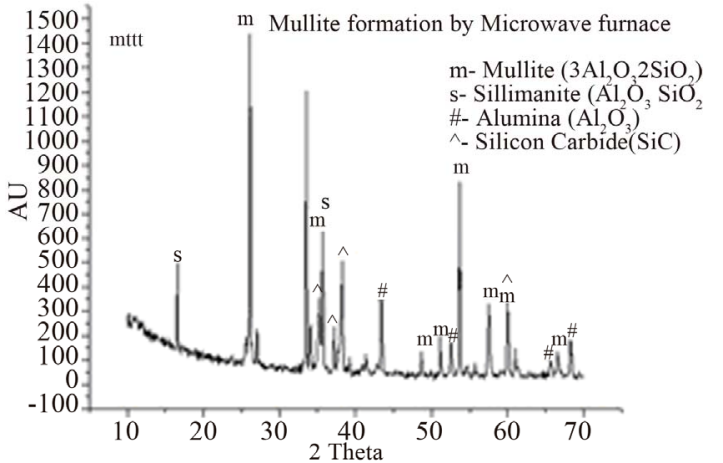

(a)

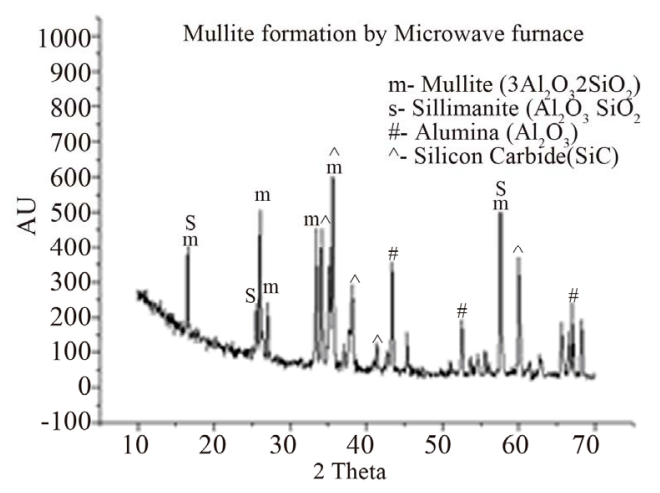

(b)

Figure 9. XRD patterns of mullite formation (Cu Target) in (a) microwave furnace (a) and (b) conventional furnace.

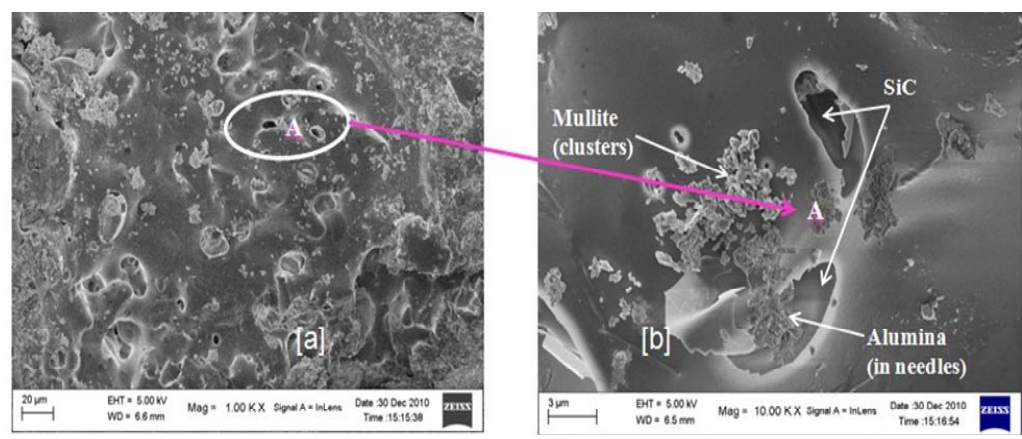

Figure 10. Morphological features of mullite (cluster), alumina (needle shape) and silicon carbide (massive structure) at one location. Figure 10(a). shows the image with $1 \mathrm{~K}$ mag. image; Figure 10(b). shows the image of spot A of Figure 10(a), which is enlarged to $10 \mathrm{~K}$ mag. 

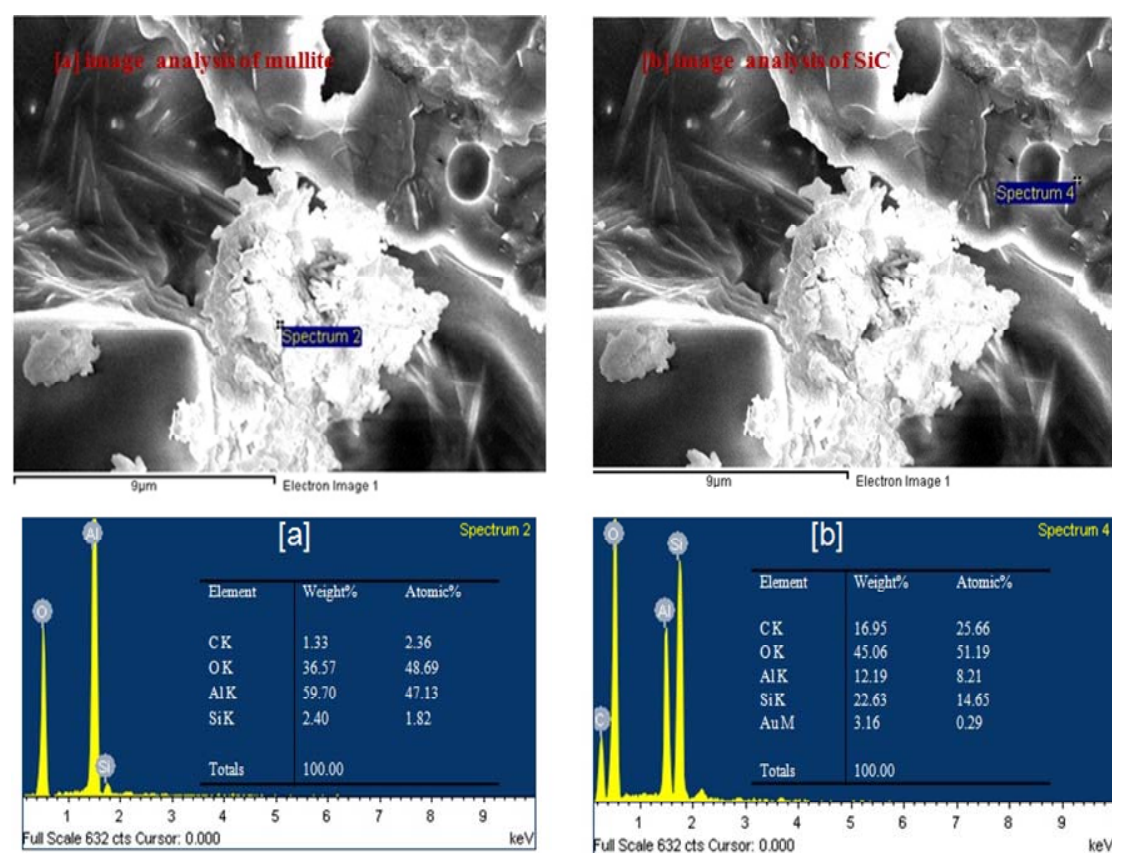

Figure 11. SEM-EDAX data of mullite and SiC. (a). image and spectrum analysis of mullite; (b). image and spectrum analysis of $\mathrm{SiC}$.
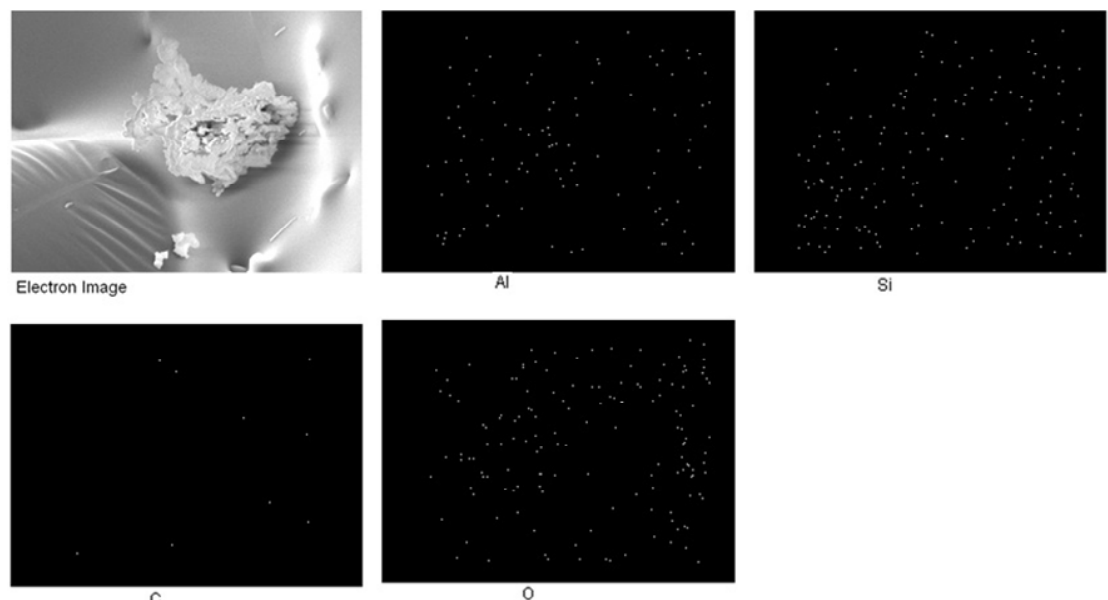

Figure 12. Image mapping of $\mathrm{Al}, \mathrm{Si}, \mathrm{C}$ and $\mathrm{O}$ for typical mullite sample prepared from red sediment placer sillimanite.

prepared from the red sediment placer sillimanite as a value addition.

\section{Conclusions}

The following conclusions are drawn from the study on value addition to red sediment placer sillimanite using microwave energy and in depth structural and morphological characterisation of mullite.

- A mullite formation is seen when $60 \% \mathrm{SiC}$ and $5 \%$ binder are used with the composite charge material i.e. sillimanite $(60 \%)$ and $\mathrm{Al}_{2} \mathrm{O}_{3}(40 \%)$. The maximum temperature of the microwave sintering furnace achieved is $1355^{\circ} \mathrm{C}$ at $2450 \mathrm{~W}$ microwave power.

- Addition of $10 \%$ binder to the same charge material with $60 \% \mathrm{SiC}$, the furnace temperature achieved is $1384^{\circ} \mathrm{C}$ at microwave power $1900 \mathrm{~W}$.

- A mullite is formed within 25 minutes from the sillimanite, under the above experimental conditions.

- Whereas under the similar additive conditions, the mullite formed from sillimanite in conventional furnace heating, it took more than 3 hours at $1300^{\circ} \mathrm{C}$.

- The XRD data is shows mullite phase which relatively distinct from the formation mullite using microwave furnace than conventional furnace.

- FESEM image analysis shows the mullite and silicon carbide in microwave treated sample.

- The SEM EDAX and image mapping data also confirm the findings of mullite and silicon carbide. 
- Thus microwave heat source is much effective for value addition to red sediment placer sillimanite to form mullite in compare to conventional furnace.

\section{Acknowledgements}

Er. Satya Sai Srikant is very much thankful to the Prof. B. K. Mishra, Director, CSIR-Institute of Minerals and Materials Technology, Bhubaneswar for giving permission to utilize infrastructural facilities of CSIR-IMMT and for his encouragements to do Ph.D. (Registered at SOA University; Bhubaneswar, Odisha, India) and publication of papers.

\section{REFERENCES}

[1] S. Tripathi and G. Banerjee, "Synthesis and Mechanical Properties of Mullite from Beach sand Sillimanite: Effect of $\mathrm{TiO}_{2}$," European Journal Ceramic Society, Vol. 18, No. 14, 1998, pp. 2081-2087. doi:10.1016/S0955-2219(98)00149-6

[2] E. Fagury and R. Kiminami, " $\mathrm{Al}_{2} \mathrm{O}_{3} /$ Mullite/SiC Powders Synthesized by Microwave-Assisted Carbothermal Reduction of Kaolin," Ceramics International, Vol. 27, No. 7, 2001, pp. 815-819. doi:10.1016/S0272-8842(01)00035-9

[3] T. Ebadzadeh, M. H. Sarrafi and E. Salahi, "MicrowaveAssisted Synthesis and Sintering of Mullite," Ceramics International, Vol. 35, No. 8, 2009, pp. 3175-3179. doi:10.1016/i.ceramint.2009.05.013
[4] Y. Fang, Y. Chen and M. R. Silsbee, "Microwave Sintering of Fly Ash," Material Letter, Vol. 27, No. 4-5, 1996, pp. 155-159. doi:10.1016/0167-577X(96)80007-3

[5] R. B. Rao and N. Patnaik, "Microwave Energy in Mineral Processing - A Review," Journal of the Institution of Engineers (India)—Mining, Vol. 84, No. 2, 2004, pp. 56-61.

[6] C. A. Pickles, "Microwaves in Extractive Metallurgy: Part 1-A Review of Applications," Minerals Engineering, Vol. 22, No. 13, 2009, pp. 1102-1111. doi:10.1016/j.mineng.2009.02.015

[7] E. T. Thostenson and T.W. Chou, "Microwave Processing: Fundamentals and Applications," Composites Part A: Applied Science and Manufacturing, Vol. 30, No. 9, 1999, pp. 1055-1071. doi:10.1016/S1359-835X(99)00020-2

[8] D. E. Clark and W.H. Sutton, "Microwave Processing of Ceramic Materials," Annual Review of Materials Science, Vol. 26, 1996, pp. 229-231. doi:10.1146/annurev.ms.26.080196.001503

[9] S. S. Srikant, P. S. Mukherjee and R. B. Rao, "Microwave Reduction of Placer Ilmenite Concentrate," Mineral Processing Technology, 2011.

[10] H. Kozuka and J. D. Mackenzie, "Microwave Synthesis of Metal Carbides," Ceramic Transactions, Vol. 21, 1991, pp. 387-394.

[11] A. C. D. Chaklader, S. D. Gupta, E. C. Y. Lin and B. Gutowski, " $\mathrm{Al}_{2} \mathrm{O}_{3} / \mathrm{SiC}$ Composites from Aluminosilicates Precursors," Journal of the American Ceramic Society, Vol. 75 , No. 8, 1992, pp. 2283-2285. 